\title{
CARACTERIZAÇÃO DE BIOMASSAS DE UVA-DO-JAPÃO E BAGAÇO DE MALTE COMO ADSORVENTES ATRAVÉS DA ANÁLISE DO PONTO DE CARGA ZERO
}

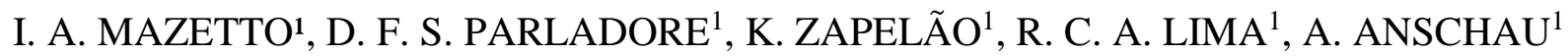

${ }^{1}$ Universidade Tecnológica Federal do Paraná, Engenharia de Bioprocessos e Biotecnologia.

E-mail para contato: ingrid.mazetto@hotmail.com

\begin{abstract}
RESUMO - O efeito do $\mathrm{pH}$ é um fator de grande importância nos processos de adsorção, e a caracterização dos materiais utilizados nesses processos é de extrema importância para se entender e buscar uma melhor eficiência. Por isso, o presente estudo teve como objetivo comparar a biomassa in natura de uva-doJapão (Hovenia dulcis Thunberg) e o bagaço de malte através do ponto de carga zero ( $\mathrm{pH} \mathrm{PCZ}_{\mathrm{P}}$ ). A uva-do-Japão foi colhida na fazenda experimental da UTFPR, câmpus Dois Vizinhos, e o bagaço de malte é proveniente da micro cervejaria Schaff Bier, localizada em Francisco Beltrão. Ambas as biomassas foram secas em estufa, moídas em moinho de facas e separadas por granulometria. Em seguida foram colocadas em Erlenmeyers com solução de $\mathrm{NaCl}$ 0,1 mol.L $\mathrm{L}^{-1}$, em pHs ajustados de 1 a 11, e mantidas em Shaker com agitação de $100 \mathrm{rpm}$, por tempo pré-determinado. $\mathrm{O}$ resultado foi calculado a partir da diferença das médias aritméticas dos pontos finais e iniciais. $\mathrm{O}$ pHPCZ encontrado para o bagaço de malte foi de 6,65 e para a biomassa de uva-do-Japão, de 6,00, ambos em torno da neutralidade, o que os torna úteis em processos tanto para corantes aniônicos, como para corantes catiônicos. Este fato também é vantajoso, tendo em vista que requer pouco ou nenhum ajuste de $\mathrm{pH}$, o que pode encarecer e atrasar o processo.
\end{abstract}

\section{INTRODUÇÃO}

A técnica de adsorção é utilizada em processos de descontaminação de efluentes, onde o contaminante da fase liquida é adsorvido por um material adsorvente. O adsorvente mais utilizado é o carvão ativado, que possui boa capacidade adsorvente devido à área superficial, tamanho e volume dos poros. Porém, uma série de adsorventes alternativos vem sendo estudados, já que o custo do carvão ativado comercial é muito alto (Marín, 2015). Resíduos industriais como sabugo de milho, serragem e bagaço de cana-de-açúcar vem se destacando por apresentarem características semelhantes à do carvão comercial, além de um custo muito mais baixo (Rocha, 2012).

Um dos fatores de maior importância nos processos de adsorção é o efeito do pH no meio. Esse fato interfere na capacidade adsortiva dos bioadsorventes, devido a competição existente por sítios ativos e espécies protônicas e os íons metálicos (Freitas, 2015). 
Dessa forma, uma caracterização de extrema importância para materiais adsorventes é o ponto de carga zero ( $\mathrm{pH}$ PCZ). Esse parâmetro indica o valor do $\mathrm{pH}$ no qual um sólido possui carga eletricamente nula em sua superfície, ou seja, o número de cargas positivas e negativas é o mesmo. Dessa forma é possível prever a carga da superfície do adsorvente em função do $\mathrm{pH}$ e assim entender a relação entre os efeitos do $\mathrm{pH}$ e a eficiência de adsorção em alguns processos (Deolin, 2013).

Com base nisso, este trabalho tem como objetivo comparar biomassas de pseudofruto de uva-do-Japão e bagaço de malte como possíveis bioadsorventes através do ponto de carga zero (pHPCZ).

\section{MATERIAIS E MÉTODOS}

\subsection{Preparo dos materiais adsorventes}

A uva-do-Japão foi colhida na fazenda experimental da UTFPR, câmpus Dois Vizinhos. O pseudofruto foi separado da casca e semente, seco em estufa e moído até obtenção de biomassa com granulometria de 60 mesh.

O bagaço de malte foi cedido pela micro cervejaria Schaff Bier, localizada na cidade de Francisco Beltrão, Paraná. Este foi lavado em água corrente para eliminação de impurezas e seco em estufa. Após, o material foi moído em moinho de facas até obtenção de biomassa com granulometria 35 mesh.

\subsection{Procedimento para a análise do $\mathrm{pH} P \mathrm{PCZ}$}

Em erlenmeyers de $125 \mathrm{~mL}$ foram adicionados $0,2 \mathrm{~g}$ do devido adsorvente e $20 \mathrm{~mL}$ de solução de $\mathrm{NaCl}$ a 0,1 mol. $\mathrm{L}^{-1}$ com valores de $\mathrm{pH}$ de 1 a 11 ajustados com soluções de $\mathrm{NaOH}$ e $\mathrm{HCl}$ 0,1 mol.L $\mathrm{L}^{-1}$. Os ensaios foram realizados em duplicadas. Nos ensaios com a uva-doJapão, o equilíbrio ocorreu em $1 \mathrm{~h}$ e para o bagaço de malte, $24 \mathrm{~h}$. Após o equilíbrio em banho termostático, sob agitação de $100 \mathrm{rpm}$, a $25^{\circ} \mathrm{C}$, as soluções foram filtradas e o pH final da solução anotado. $\mathrm{O}$ pHPCZ neste caso, foi correspondente à faixa na qual o pH final é constante independente do $\mathrm{pH}$ inicial (tamponamento).

\section{RESULTADOS E DISCUSSÃO}

Os processos de adsorção são fortemente dependentes do $\mathrm{pH}$ do meio, afetando a carga superficial do adsorvente, além do grau de ionização e as espécies do adsorvato (Elliott; Huang, 1981). Este fato justifica o estudo da eficiência da adsorção do corante em uma ampla faixa de $\mathrm{pH}$, bem como a determinação do pHPCZ do adsorvente.

Nas Figuras 1 e 2 observa-se a relação do $\mathrm{pH}$ inicial e o $\mathrm{pH}$ final das soluções preparados no experimento com a biomassa da uva-do-Japão in natura e com o bagaço de malte. 
Figura 1 - Ponto de carga zero da biomassa de uva-do-Japão.

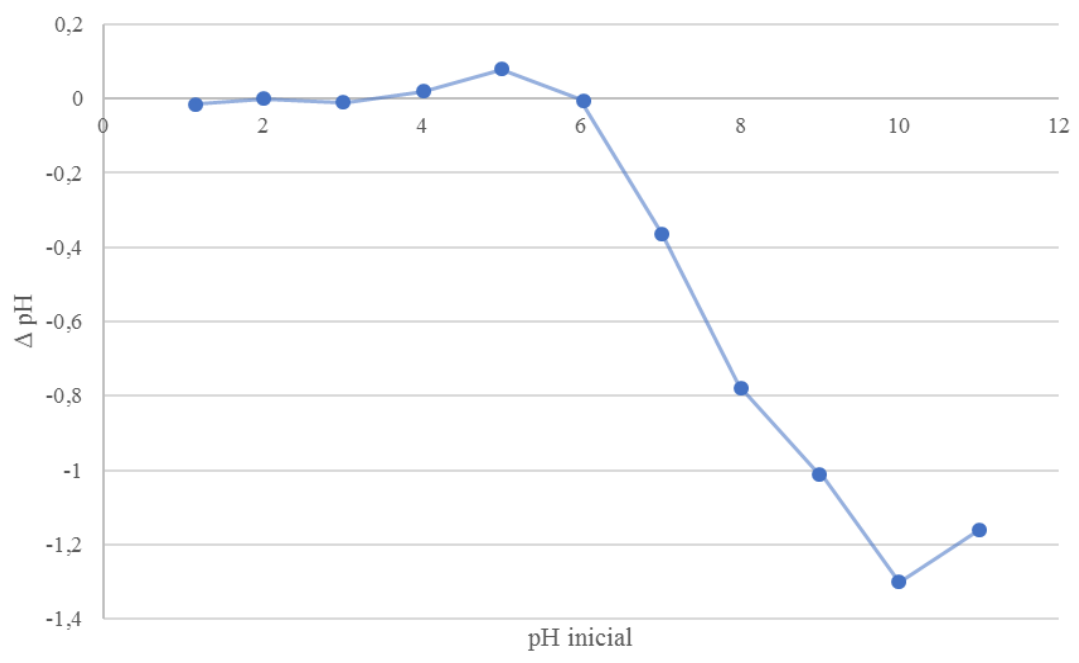

Figura 2 - Ponto de carga zero do bagaço de malte.

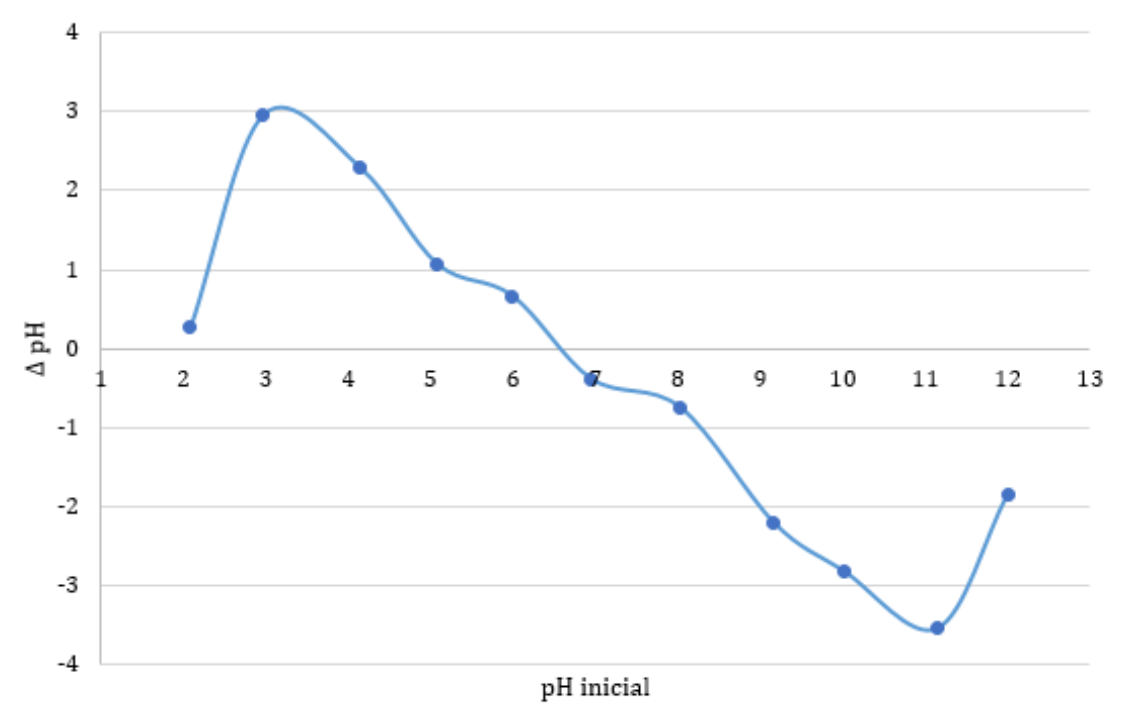

Com base nos experimentos, foi possível observar que a uva-do-Japão possui ponto de carga zero de 6,0 e o bagaço de malte 6,65. Sabe-se que, em soluções com pH abaixo do pHPCZ a superfície é carregada positivamente e um grande numero de ânions é adsorvido para balancear as cargas positivas. O oposto também é valido e em soluções com $\mathrm{pH}$ acima do

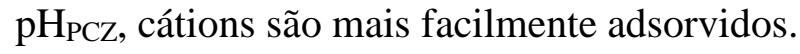

Freitas et al. (2015) obteve pH $\mathrm{PCZ}_{\mathrm{C}}$ de algumas biomassas proveniente de cascas de materiais in natura. Já Silva et al. (2010), obteve o pHPCZ do pó do pseudocaule da bananeira. Os valores de pHPCZ obtidos por ambos e os resultados obtidos neste estudo estão dispostos na Tabela 1. 
Tabela 1 - Resultados dos ensaios de pHPCZ.

\begin{tabular}{cc}
\hline Bioadsorvente & Ponto de Carga Zero (pHPCz) \\
\hline Arroz $^{\mathbf{1}}$ & 5,38 \\
Banana $^{\mathbf{1}}$ & 7,21 \\
Coco $^{1}$ & 4,43 \\
Laranja $^{\mathbf{1}}$ & 6,73 \\
Mamão $^{\mathbf{1}}$ & 5,36 \\
Maracujá $^{\mathbf{1}}$ & 4,94 \\
Melancia $^{1}$ & 6,05 \\
Melão $^{\mathbf{1}}$ & 6,31 \\
Pseudocaule de $^{\mathbf{B}}$ & 5,70 \\
Bananeira $^{\mathbf{2}}$ & 6,00 \\
Uva-do-Japão $^{\mathbf{3}}$ & 6,65 \\
Bagaço de Malte $^{\mathbf{3}}$ &
\end{tabular}

${ }^{1}$ Freitas et al. (2015); ${ }^{2}$ Silva et al. (2010); ${ }^{3}$ Presente trabalho.

Nota-se que os pontos de carga zero de biomassas in natura são dos mais variados, abrangindo uma faixa de 4 a 7,5, o que implica na característica específica de cada um e gera respostas diferentes para cada tipo de corante.

\section{CONCLUSÃO}

Conhecer o ponto de carga zero do material do adsorvente é de grande importância no processo de adsorção, pois pode ser um parâmetro ajustado para otimização do mesmo.

Ambas as biomassas utilizadas nesse estudo possuem $\mathrm{pH} \mathrm{PCZ}_{\mathrm{PC}} \mathrm{em}$ torno da neutralidade. Com base nisso, podem ser utilizados tanto corantes aniônicos como corantes catiônicos, sem que o bioadsorvente perca muito das características e com a mesma eficiência.

Uma vez que esse pHPCz seja quase neutro, há pouco (ou nenhum) ajuste de $\mathrm{pH}$ em um efluente de interesse, o que economiza tempo e evita o uso de reagentes químicos que deixam o processo mais caro.

\section{REFERÊNCIAS}

DEOLIN, M. H. da S.; FAGNANI, H. M. C.; ARROYO, P. A.; BARROS, M. A. S. D. Obtenção do ponto de carga zero de materiais adsorventes. VIII EPCC, Maringá, 2013.

ELliOTT, H. A.; HUANG, C. P. Adsorpion characteristics of some $\mathrm{Cu}(\mathrm{II})$ complexes on aluminosilicates. Water Reasearch, v. 15, 849 - 955, 1981. 
FREITAS, F. B. A. de; CÂMARA, M. Y. de F.; MARTINS, D. F. F. Determinação do PCZ de adsorventes naturais utilizados na remoção de contaminantes em soluções aquosas. Blucher Chemistry Proceedings, v. 3, n. 1, nov. 2015.

MARÍN, S. L. A. Remoção dos corantes têxteis C.I. Reactive Blue 203 e Reactive Red 195 mediante o uso de bagaço de maçã como adsorvente. Dissertação de Mestrado. Universidade Tecnológica Federal do Paraná. Pato Branco, 2015.

ROCHA, O. R. S. da; NASCIMENTO, G. E. do; CAMPOS, N. F.; SILVA, V. L. da; DUARTE, M. M. M. B. Avaliação do processo adsortivo utilizando mesocarpo de coco verde para remoção do corante Cinza Reativo BF-2R. Quím. Nova, v. 35, n. 7, 13691374, 2012.

SILVA, F. M. da; SANTANA, S. A. A.; BEZERRA, C. W. B; SILVA, H. A. dos S. Adsorção do corante têxtil Azul de Remazol R por pseudocaule da bananeira (Musa sp). Cad. Pesq., São Luís, v. 17, n. 3, set/dez. 2010. 